\title{
The prognostic impact of pretreatment anemia in patients with gastric cancer and nonhypoalbuminemia undergoing curative resection: a retrospective study
}

\author{
Jianlong Jiang ${ }^{1 \#}$, Jun Ouyang ${ }^{1,2 \#}$, Shuhao Liu ${ }^{1}$, Jingyao Chen ${ }^{1}$, Hao Zhang ${ }^{3}$, Chunfei Wang ${ }^{1}$, Wenhui Wu ${ }^{1}$, \\ Changhua Zhang ${ }^{1}$, Yulong $\mathrm{He}^{1}$ \\ ${ }^{1}$ Digestive Disease Center, Seventh Affiliated Hospital, Sun Yat-sen University, Shenzhen, China; ${ }^{2}$ Department of Gastrointestinal Surgery, First \\ Affiliated Hospital, Sun Yat-sen University, Guangzhou, China; ${ }^{3}$ General Surgery Department, Seventh Affiliated Hospital, Sun Yat-sen University, \\ Shenzhen, China \\ Contributions: (I) Conception and design: W Wu, C Zhang, Y He; (II) Administrative support: H Zhang, C Wang; (III) Provision of study materials \\ or patients: C Zhang, Y He; (IV) Collection and assembly of data: J Jiang, J Ouyang, S Liu; (V) Data analysis and interpretation: J Jiang, J Ouyang, H \\ Zhang; (VI) Manuscript writing: All authors; (VII) Final approval of manuscript: All authors. \\ \#These authors contributed equally to this work. \\ Correspondence to: Changhua Zhang; Yulong He. Digestive Disease Center, Seventh Affiliated Hospital, Sun Yat-sen University, Shenzhen, China. \\ Email: zhchangh@mail.sysu.edu.cn; heyulong@mail.sysu.edu.cn.
}

\begin{abstract}
Background: The influence of pretreatment anemia on the prognosis of patients with advanced gastric cancer (GC) remains controversial. We retrospectively examined the impact of pretreatment anemia on the overall survival (OS) of patients with GC with nonhypoalbuminemia undergoing curative resection.

Methods: The clinicopathological data of 2,916 patients with advanced GC who received a radical gastrectomy from 1994 to 2015 were analyzed. The patients were divided into two subgroups by hemoglobin level, $<120$ and $\geq 120 \mathrm{~g} / \mathrm{L}$. OS was analyzed using the Kaplan-Meier method, and a multivariate Cox proportional hazards model was used to identify the independent prognostic factor.

Results: A total of 1,099 patients were included in our study. The median follow-up duration was 43 (IQR, 24-66) months. The prevalence of anemia was 40.9\%. Among these 1,099 patients, 505 (46.0\%) had nonhypoalbuminemia. Kaplan-Meier survival analysis showed that patients with GC who were anemic had a poorer OS than patients who were not (5-year OS rate: $58.4 \%$ vs. $66.8 \%, \mathrm{P}<0.0001)$. Multivariate analysis revealed that pretreatment anemia was an independent prognostic factor [hazard ratio $(\mathrm{HR})=1.455,95 \% \mathrm{CI}$, 1.013-2.09; $\mathrm{P}=0.043]$.

Conclusions: Our findings indicate that pretreatment anemia may serve as an independent prognostic factor for patients with advanced GC with nonhypoalbuminemia after radical gastrectomy, especially those with larger tumor size and pT3 disease.
\end{abstract}

Keywords: Gastric cancer (GC); prognosis pretreatment anemia; non-hypoalbuminemia

Submitted Apr 04, 2021. Accepted for publication May 21, 2021.

doi: 10.21037/atm-21-1649

View this article at: https://dx.doi.org/10.21037/atm-21-1649

\section{Introduction}

Cancer-related anemia is one of the most common comorbidities of malignancy. The prevalence of pretreatment anemia has been reported to be $30-90 \%$ in various cancers (1). Previous studies have reported that tumor-associated blood loss, bone marrow involvement, cytokine-mediated disorder, and nutritional deficiencies in iron or folic acid play a crucial role in the initiation and maintenance of cancer-related anemia (2). Pretreatment anemia is commonly observed in cancer patients and 
adversely affects the quality of life (QOL) and survival of these patients $(3,4)$.

Gastric cancer (GC) is the fifth most common cancer diagnosed worldwide. GC is the third most common cause of cancer-related deaths (5). Currently, the best strategies for GC are prevention and personalized treatments (6). To date, much effort has been devoted to searching for prognostic factors that may help to precisely calculate the risk of prognosis or recurrence in patients with GC after curative resection. In a Korean cohort that enrolled 1,688 patients with GC who underwent radical gastrectomy, the authors indicated that pretreatment anemia was an independent predictor for overall survival (OS) in TNM stage I and II GC (7). However, in a subsequent Chinese study, the researchers emphasized that it was in TNM stage III, rather than in stages I and II, that pretreatment anemia could serve as an independent prognostic factor for OS (8). Another study presented evidence that pretreatment anemia was not an independent factor for survival (9). The reasons for these inconsistencies could be complex and various across studies. One of the most important reasons for the inconsistencies could be the interference of confounding factors. Chronic occult bleeding, alimentary obstruction, severe complications, malnutrition, weight loss and renal dysfunction are common confounding factors that can also cause pretreatment anemia when initially diagnosed. To control for bias from these confounding factors, we further evaluated the prognostic influence of pretreatment anemia on the survival outcomes of patients with GC with nonhypoalbuminemia.

We present the following article in accordance with the STROBE reporting checklist (available at https://dx.doi. org/10.21037/atm-21-1649).

\section{Methods}

Patients who underwent curative resection for advanced GC between January 1994 and December 2015 were identified from the GC database of the First Affiliated Hospital of Sun Yat-sen University (FAHSYSU) in Guangzhou, China. The exclusion criteria were as follows: patients with remnant stomach cancer or recurrent carcinoma, patients with a personal history of malignancy, patients who received preoperative chemotherapy, in situ carcinoma, patients with stage IV and distant metastasis and patients for whom inadequate follow-up data were available. The study was conducted in accordance with the Declaration of Helsinki (as revised in 2013). Ethical approval was obtained from the Medical Ethics Committee of the Seventh affiliated Hospital of Sun Yat-sen University (No: KY-2020-024-01). Individual consent for this retrospective analysis was waived.

\section{Clinical data collection and processing}

The following data were collected directly from our GC database by review of the medical records, and no additional calculations or processing were required: age at surgery, sex, tumor size, primary tumor site, preoperative serum carcinoembryonic antigen (CEA) level (ng/mL), Borrmann's classification, type of lymphadenectomy, degree of tumor differentiation, and follow-up status. Moreover, the postoperative pathological T stage (pT), $\mathrm{N}$ stage $(\mathrm{pN})$, and final TNM stage were re-encoded according to the eighth American Joint Committee on Cancer TNM staging system. Peripheral blood samples were collected within 1 week before treatment from all patients. Anemia was defined as a preoperative hemoglobin $(\mathrm{Hb})$ level $<120 \mathrm{~g} / \mathrm{L}$ according to the National Comprehensive Cancer Network (NCCN) recommendations (10). Patients were classified into two groups according to this definition: the anemic group $(\mathrm{Hb}<120 \mathrm{~g} / \mathrm{L})$ and the nonanemic group $(\mathrm{Hb} \geq 120 \mathrm{~g} / \mathrm{L})$, as previously reported $(11,12)$.

\section{Follow-up and study end-points}

After curative surgery, all patients were evaluated every three months in the first 2 years, every 6 months in the subsequent 3 years, and then every year or until death. The follow-up program was composed of a physical examination, a serum tumor marker evaluation, an endoscopy, and abdominal computed tomographic scans. The last follow-up date was December 2019.

The study end-point was OS. OS was defined as the duration from the surgery date to either the date of death or the date of the last follow-up. OS rates and $95 \%$ confidence intervals (CIs) were determined using the Kaplan-Meier estimator. The log-rank test was used to identify differences between the survival curves of different patient groups.

\section{Statistical analysis}

Values are expressed as the mean \pm standard deviation (SD) for continuous variables and frequencies (percent) for categorical variables. Groups were compared using the chi-square test and Fisher's exact test. OS rates and 95\% CIs were estimated via the Kaplan-Meier method and 


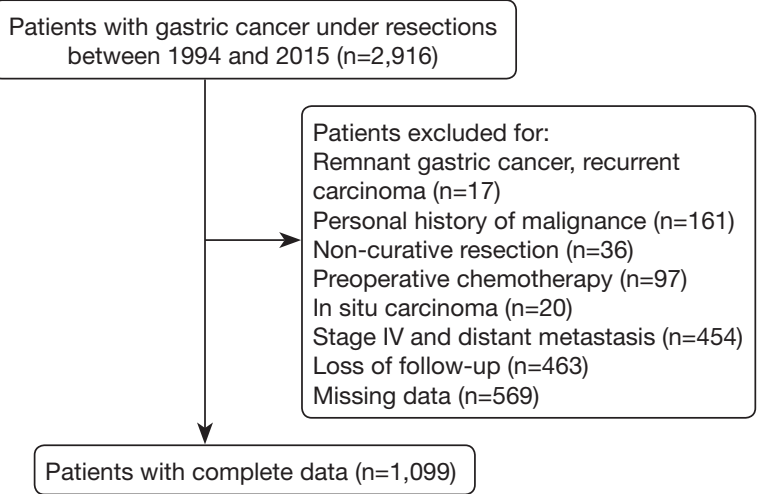

Figure 1 Flowchart describing patient enrollment and exclusion.

were compared to the log-rank test to validate the survival curves. Variables conforming to the proportional hazards assumption were enrolled in the univariate analysis, and those with $\mathrm{P}<0.1$ were further included in the multivariate analysis. Multivariate analyses were also performed using the Cox proportional hazards model to identify independent prognostic factors through the enter method. All statistical tests were two-tailed, and $\mathrm{P}$ values less than 0.05 were considered significant. Data were analyzed using SPSS (Windows version 22.0; Chicago, IL, USA).

The following clinicopathological features were analyzed: (I) sex (male or female); (II) age at surgery $(\leq 60$ or $>60$ years); (III) CEA level $(\leq 5$ or $>5 \mathrm{ng} / \mathrm{mL}$ ); (IV) tumor size $(<5$ or $\geq 5 \mathrm{~cm})$; (V) primary tumor site (lower third, middle third, upper third, or whole stomach); (VI) the depth of primary tumor invasion (pT stage); (VII) the number of positive lymph nodes (pN stage); (VIII) AJCC pathological classification (pTNM classification); (IX) the degree of tumor differentiation (well, moderate or poor); (X) Borrmann's classification of primary tumor (I, II, III, IV); and (XI) anemia (hemoglobin $<120 \mathrm{~g} / \mathrm{L}$ ).

\section{Results}

\section{Patient characteristics}

A total of 1,099 patients met the inclusion and exclusion criteria, and the flowchart shows the selection process for the study cohort (Figure 1). The overall median follow-up duration was 43 (IQR, 24-66) months. Table 1 illustrates
Table 1 General characteristics of 1,099 gastric cancer patients

\begin{tabular}{|c|c|}
\hline Characteristics & No. of patients (\%) \\
\hline \multicolumn{2}{|l|}{ Age (years) } \\
\hline$\leq 60$ & $604(55.0)$ \\
\hline$>60$ & $495(45.0)$ \\
\hline \multicolumn{2}{|l|}{ Gender } \\
\hline Male & $748(68.1)$ \\
\hline Female & 351 (31.9) \\
\hline \multicolumn{2}{|l|}{ CEA (ng/mL) } \\
\hline$\leq 5$ & 905 (82.3) \\
\hline$>5$ & $194(17.7)$ \\
\hline \multicolumn{2}{|l|}{ Primary site } \\
\hline Upper & $321(29.2)$ \\
\hline Middle & $266(24.2)$ \\
\hline Lower & $463(42.1)$ \\
\hline Whole & $49(4.5)$ \\
\hline \multicolumn{2}{|l|}{ pT stage } \\
\hline Tis & $3(0.3)$ \\
\hline $\mathrm{T} 1$ & $170(15.5)$ \\
\hline $\mathrm{T} 2$ & $137(12.5)$ \\
\hline T3 & $332(30.2)$ \\
\hline $\mathrm{T} 4$ & $457(41.6)$ \\
\hline \multicolumn{2}{|l|}{ pN stage } \\
\hline NO & $410(37.3)$ \\
\hline $\mathrm{N} 1$ & $185(16.8)$ \\
\hline N2 & $214(19.5)$ \\
\hline N3 & $290(26.4)$ \\
\hline \multicolumn{2}{|l|}{ pTNM stage } \\
\hline 1 & $243(22.1)$ \\
\hline II & $309(28.1)$ \\
\hline III & $547(49.8)$ \\
\hline \multicolumn{2}{|l|}{ Differentiation $^{\dagger}$} \\
\hline Well & $30(2.7)$ \\
\hline Moderate & $238(21.7)$ \\
\hline Poor & $828(75.3)$ \\
\hline
\end{tabular}

Table 1 (continued) 
Page 4 of 12

Table 1 (continued)

\begin{tabular}{lc}
\hline Characteristics & No. of patients (\%) \\
\hline Borrmann's classification ${ }^{\ddagger}$ & $43(3.9)$ \\
I & $286(26.0)$ \\
III & $634(57.7)$ \\
IV & $90(8.2)$ \\
Anemia & \\
No & $649(59.1)$ \\
Yes & $450(40.9)$ \\
Hypoalbuminemia & \\
No & $505(46.0)$ \\
Yes & $592(53.9)$ \\
\hline
\end{tabular}

${ }^{\dagger}$ Differentiation information missing for 3 patients $(0.27 \%)$;

${ }^{\ddagger}$ Borrmann information not applicable for 46 patients $(4.0 \%)$; ${ }^{\S}$ Hypoalbuminemia information not applicable for 2 patients $(0.18 \%)$. CEA, carcinoembryonic antigen.

the demographics and clinical features of these patients. The overall 5 -year survival rate of the study cohort was $63.3 \%$, and 624 patients were still alive at the end of our follow-up. Of these 1,099 patients, 748 (68.1\%) were men. The mean age was 58.16 years (range, $21-87$ years). The mean hemoglobin level was $119.97 \pm 26.14 \mathrm{~g} / \mathrm{L}$ (range, $38-175 \mathrm{~g} / \mathrm{L}$ ), and the overall prevalence of anemia was $40.9 \% ; 56.9 \%$ of the male patients and $43.1 \%$ of the female patients had anemia. The mean BMI (body mass index) was 21.88 \pm 3.16 (range, 13.84-34.38). The mean albumin level was $39.04 \pm 5.33$ (range, 15.0-74.0). There were 243 patients in stage I, 309 patients in stage II, and 547 patients in stage III, and the corresponding numbers of pretreatment anemic patients at each stage were 61 (13.6\%), 131 (29.1\%), and $258(57.3 \%)$, respectively. The general characteristics of these 1,099 patients are summarized in Table 1 .

In the present study, Kaplan-Meier survival analysis revealed that the pretreatment anemia was correlated with a poor prognosis (5-year survival rate $58.4 \%$ vs. $66.8 \%$ $\mathrm{P}<0.0001$, Figure $2 A$ ). Univariate and multivariate analysis was further performed, and revealed that pretreatment anemia was not an independent prognostic factor among the whole cohort (Table 2). After stratification by the level of albumin (Figure 2A,B,C), we found significant survival differences in GC patients with non-hypoalbuminemia (5-year survival rate $57.6 \% \mathrm{vs}$.
$70.5 \%, \mathrm{P}<0.0001$, Figure $2 C$ ). However, there was no difference in prognosis between the anemic group and the non-anemic group in hypoalbuminemic patients (Figure 2B, $\mathrm{P}=0.446$ ).

Among these 1,099 patients, $505(46.0 \%)$ had nonhypoalbuminemia. Of these 505 patients, $110(21.8 \%)$ were anemic, and the 5 -year OS rate was $58.4 \%$; 395 were nonanemic, and the 5 -year OS rate was $66.8 \%(\mathrm{P}<0.0001$; Figure $2 A$ ). The baseline clinicopathologic characteristics are shown in Table 3.

Spearman's rank test was used to further investigate the relationship between pretreatment anemia and the clinicopathologic variables. The statistic results are shown in Table 4. The following variables were slightly $(|\rho|<0.5)$ associated with the pretreatment hemoglobin level: sex $(\mathrm{P}<0.0001)$, BMI $(\mathrm{P}<0.046)$, tumor size $(\mathrm{P}<0.0001)$, pT stage $(\mathrm{P}=0.044)$, $\mathrm{pN}$ stage $(\mathrm{P}<0.0001)$, AJCC pathological classification (pTNM classification) $(\mathrm{P}<0.0001)$, degree of tumor differentiation $(\mathrm{P}=0.035)$, white blood cell count (WBC) $(\mathrm{P}<0.002)$, platelet $(\mathrm{PLT})$ count $(\mathrm{P}<0.0001)$ and metastatic lymph node (MLN) $(\mathrm{P}<0.0001)$.

After stratification by tumor size (Figure $3 A, B, C$ ), pN stage (Figure $4 A, B, C, D$ ) and pT stage (Figure $4 E, F, G, H$ ), we found a significant survival difference between patients with a tumor size $\geq 5 \mathrm{~cm}$ (5-year survival rate $37.4 \%$ vs. $51.1 \%, \mathrm{P}=0.041$, Figure $3 C$ ) and those with pT3 stage tumors (5-year survival rate $46.2 \%$ vs. $61.0 \%$, $\mathrm{P}=0.014$, Figure $4 G$ ). Remarkably, in our analysis of patients with stage $\mathrm{pN} 0, \mathrm{pN} 1, \mathrm{pN} 2, \mathrm{pN} 3, \mathrm{pT} 1, \mathrm{pT} 2$, and pT4 GC, the current cutoff of the hemoglobin level was not associated with improved survival $(\mathrm{P}>0.05$, Figure $4 A, B, C, D, E, F, H)$.

Univariate and multivariate Cox proportional hazard regression models were used to further identify the possible independent clinicopathological variables in patients with GC with nonhypoalbuminemia. Nine prognostic risk factors were determined in the univariate analysis, including sex, CEA level, primary tumor site, $\mathrm{pT}$ stage, $\mathrm{pN}$ stage, pTNM stage, degree of tumor differentiation, Borrmann's classification, and anemia. Nevertheless, three factors that were independently associated with OS were revealed through the multivariate analysis: $\mathrm{pT}$ stage $(\mathrm{P}=0.018), \mathrm{pN}$ stage $(\mathrm{P}<0.0001)$, and anemia $(\mathrm{HR}=1.455,95 \% \mathrm{CI}, 1.013-$ 2.09; $\mathrm{P}=0.043)$ (Table 5).

\section{Discussion}

It is still controversial whether pretreatment anemia 
A

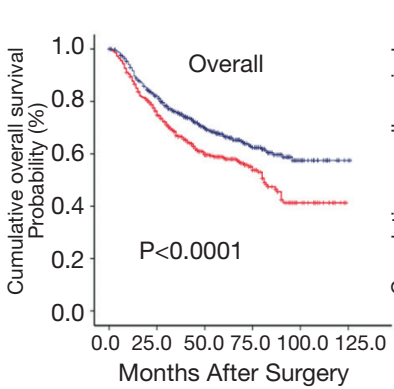

B

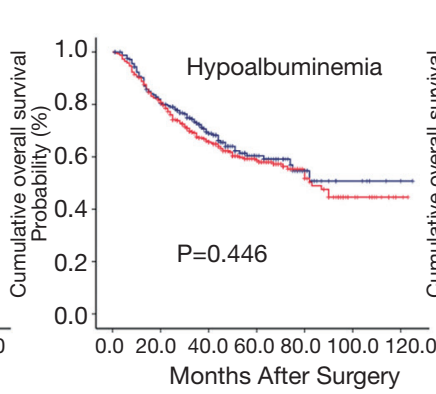

C

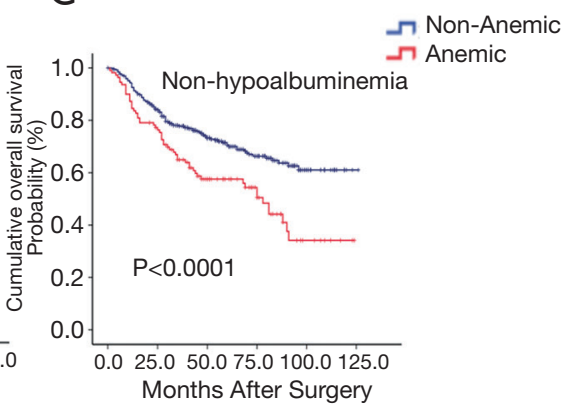

Figure 2 Kaplan-Meier curves of pretreatment anemia in the entire cohort (A), hypoalbuminemic patients (B) and non-hypoalbuminemic patients (C).

Table 2 Univariate and multivariate analysis for overall survival in the entire cohort

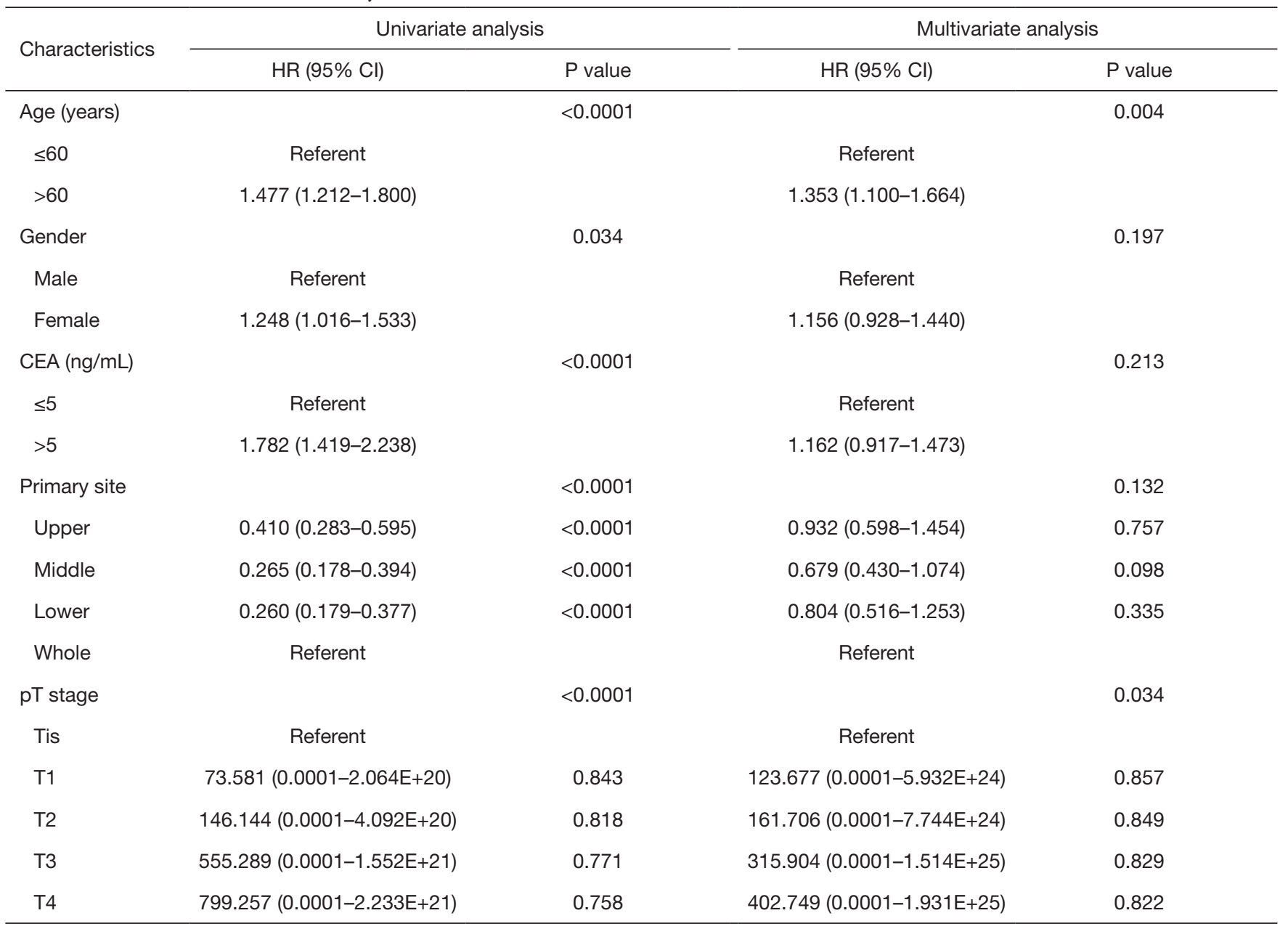

Table 2 (continued) 
Table 2 (continued)

\begin{tabular}{|c|c|c|c|c|}
\hline Characteristics & \multicolumn{2}{|c|}{ Univariate analysis } & \multicolumn{2}{|c|}{ Multivariate analysis } \\
\hline pN stage & & $<0.0001$ & & $<0.0001$ \\
\hline No & Referent & & Referent & \\
\hline N1 & $2.033(1.366-3.025)$ & $<0.0001$ & $1.280(0.792-2.068)$ & 0.314 \\
\hline N3 & 9.989 (7.355-13.566) & $<0.0001$ & $5.067(2.850-9.007)$ & $<0.0001$ \\
\hline pTNM stage & & $<0.0001$ & & 0.841 \\
\hline I & Referent & $<0.0001$ & Referent & \\
\hline II & $4.297(2.427-7.609)$ & $<0.0001$ & $1.272(0.519-3.120)$ & 0.599 \\
\hline Well & Referent & & Referent & \\
\hline Moderate & $3.038(0.953-9.677)$ & 0.06 & $1.142(0.346-3.771)$ & 0.827 \\
\hline Poor & $5.278(1.693-16.454)$ & 0.004 & $1.218(0.375-3.952)$ & 0.743 \\
\hline \multicolumn{2}{|c|}{ Borrmann's classification } & $<0.0001$ & & 0.063 \\
\hline I & $0.448(0.261-0.768)$ & 0.004 & $0.955(0.526-1.733)$ & 0.880 \\
\hline II & $0.199(0.138-0.286)$ & $<0.0001$ & $0.588(0.386-0.896)$ & 0.014 \\
\hline III & $0.463(0.349-0.615)$ & $<0.0001$ & $0.731(0.520-1.028)$ & 0.072 \\
\hline IV & Referent & & Referent & \\
\hline
\end{tabular}

CEA, carcinoembryonic antigen; $\mathrm{HR}$, hazard ratio; $\mathrm{Cl}$, confidence interval.

is associated with poor survival in advanced GC. We retrospectively analyzed a large cohort of Chinese patients with GC who underwent curative resection at our single center to resolve this issue. The prevalence of anemia in our cohort was $40.4 \%$, consistent with a large European survey (12). We found that pretreatment anemia was significantly correlated with poor OS in GC patients with nonhypoalbuminemia. Moreover, we determined that pretreatment anemia was an independent prognostic predictor for OS in these patients through a multivariate analysis.

Our findings were similar to those of previous studies, which have shown a correlation between pretreatment anemia and OS. In a cohort of 504 patients with advanced
GC, Zhang et al. reported that almost $61 \%$ of the patients had pretreatment anemia, and a lower hemoglobin level indicated a poorer $\mathrm{OS}(\mathrm{HR}=1.37, \mathrm{P}=0.037)(13)$. However, it is noteworthy that there was a high rate of pretreatment anemia in their cohort. In a recent study, $27.0 \%$ of patients in the cohort were anemic, and Liu et al. found that preoperative anemia was independently related to poor OS in patients with TNM stage III GC rather than stage I and II GC (8). Similarly, the same trend can be seen in non-alimentary tract cancer. In a study of 2,123 breast cancer patients, the incidence of anemia was $25.2 \%$, and pretreatment anemia was an independent prognostic factor for lymph node metastasis-free survival, relapse-free survival and OS (11). Of note, anemia is more common 
Table 3 Baseline characteristics of pretreatment anemia among non-hypoalbuminemia patients

\begin{tabular}{|c|c|c|c|c|}
\hline Characteristics & Anemic & Nonanemic & $\chi^{2}$ & $\mathrm{P}$ \\
\hline Total & $110(21.8 \%)$ & 395 (78.2\%) & & \\
\hline Age (years) & & & 0.111 & 0.739 \\
\hline$\leq 60$ & 74 (67.3\%) & $259(65.6 \%)$ & & \\
\hline$>60$ & 36 (32.7\%) & $136(34.4 \%)$ & & \\
\hline Gender & & & 28.207 & $<0.0001$ \\
\hline Male & $53(48.2 \%)$ & 295 (74.7\%) & & \\
\hline Female & 57 (51.8\%) & $100(25.3 \%)$ & & \\
\hline CEA (ng/mL) & & & 1.146 & 0.284 \\
\hline$\leq 5$ & 95 (86.4\%) & $324(82.0 \%)$ & & \\
\hline$>5$ & 15 (13.6\%) & 71 (18.0\%) & & \\
\hline Primary site $^{\dagger}$ & & & 3.249 & 0.343 \\
\hline Upper & 27 (24.5\%) & $122(30.9 \%)$ & & \\
\hline Middle & $33(30.0 \%)$ & $90(22.8 \%)$ & & \\
\hline Lower & $46(41.8 \%)$ & $171(43.3 \%)$ & & \\
\hline Whole & $4(3.6 \%)$ & 12 (3.0\%) & & \\
\hline pT stage & & & 8.792 & 0.057 \\
\hline Tis & $1(0.9 \%)$ & $1(0.3 \%)$ & & \\
\hline $\mathrm{T} 1$ & 12 (10.9\%) & $86(21.8 \%)$ & & \\
\hline T2 & $14(12.7 \%)$ & 55 (13.9\%) & & \\
\hline T3 & $40(36.4 \%)$ & $120(30.4 \%)$ & & \\
\hline $\mathrm{T} 4$ & $43(39.1 \%)$ & $133(33.7 \%)$ & & \\
\hline pN stage & & & 16.923 & 0.001 \\
\hline NO & 34 (30.9\%) & $173(43.8 \%)$ & & \\
\hline N1 & $11(10.0 \%)$ & $72(18.2 \%)$ & & \\
\hline N2 & $28(25.5 \%)$ & 74 (18.7\%) & & \\
\hline N3 & 37 (33.6\%) & 76 (19.2\%) & & \\
\hline pTNM stage & & & 13.265 & 0.001 \\
\hline I & $20(18.2 \%)$ & $120(30.4 \%)$ & & \\
\hline II & 24 (21.8\%) & $114(28.9 \%)$ & & \\
\hline III & $66(60.0 \%)$ & $161(40.8 \%)$ & & \\
\hline Differentiation $^{\dagger}$ & & & 5.145 & 0.076 \\
\hline Well & $1(0.9 \%)$ & 16 (4.1\%) & & \\
\hline Moderate & 20 (18.2\%) & 97 (24.6\%) & & \\
\hline Poor & $89(80.9 \%)$ & $281(71.3 \%)$ & & \\
\hline
\end{tabular}

Table 3 (continued)
Table 3 (continued)

\begin{tabular}{lrrrr}
\hline Characteristics & Anemic & Nonanemic & $\chi^{2}$ & P \\
\hline Borrmann's classification & & & 3.210 & 0.353 \\
I & $1(0.9 \%)$ & $13(3.4 \%)$ & & \\
II & $28(26.4 \%)$ & $119(31.4 \%)$ & & \\
III & $68(64.2 \%)$ & $223(58.8 \%)$ & & \\
IV & $9(8.5 \%)$ & $24(6.3 \%)$ & \\
\hline
\end{tabular}

${ }^{\dagger}$ Differentiation information missing for 1 patients $(0.19 \%)$. ${ }^{\ddagger}$ Borrmann information missing for 20 patients (3.9\%). CEA, carcinoembryonic antigen.

Table 4 Spearman's rank test of the correlation between hemoglobin levels and clinical characteristics

\begin{tabular}{lcc}
\hline Characteristics & $\mathrm{P}(\mathrm{Hb})$ & $\mathrm{P}$ \\
\hline Age & -0.015 & 0.739 \\
Sex & 0.236 & $<0.0001$ \\
CEA & -0.048 & 0.285 \\
BMI & -0.103 & 0.046 \\
Tumor size & 0.157 & $<0.0001$ \\
Primary site & 0.024 & 0.596 \\
pT stage & 0.09 & 0.044 \\
pN stage & 0.16 & $<0.0001$ \\
pTNM stage & 0.158 & $<0.0001$ \\
Differentiation & 0.094 & 0.035 \\
Borrmann'classification & 0.074 & 0.103 \\
WBC & -0.141 & 0.002 \\
PLT & 0.215 & $<0.0001$ \\
MLN & 0.172 & $<0.0001$ \\
\hline
\end{tabular}

CEA, carcinoembryonic antigen; BMI, body mass index; WBC, white blood cell count; PLT, platelet; MLN, metastatic lymph node.

in alimentary tract cancer than in non-alimentary tract cancer (14), and various factors can lead to anemia, which might be related to tumors (large size and deep invasion), patients (malnutrition, weight loss, and renal dysfunction), or complications (obstruction, bleeding, and perforation). These findings may indicate that the function of anemia in relation to cancer-specific survival is different and complicated in alimentary tract cancer compared to the role of anemia in non-alimentary tract cancer. Researchers found 

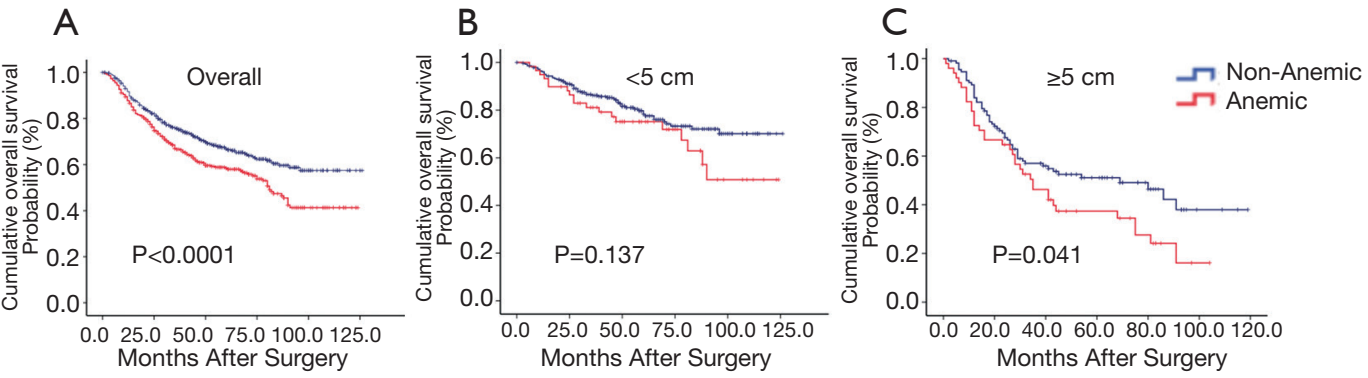

Figure 3 Kaplan-Meier curves of pretreatment anemia in nonhypoalbuminemia patients among groups: (A) overall; (B) tumor size <5 cm; (C) tumor size $\geq 5 \mathrm{~cm}$.
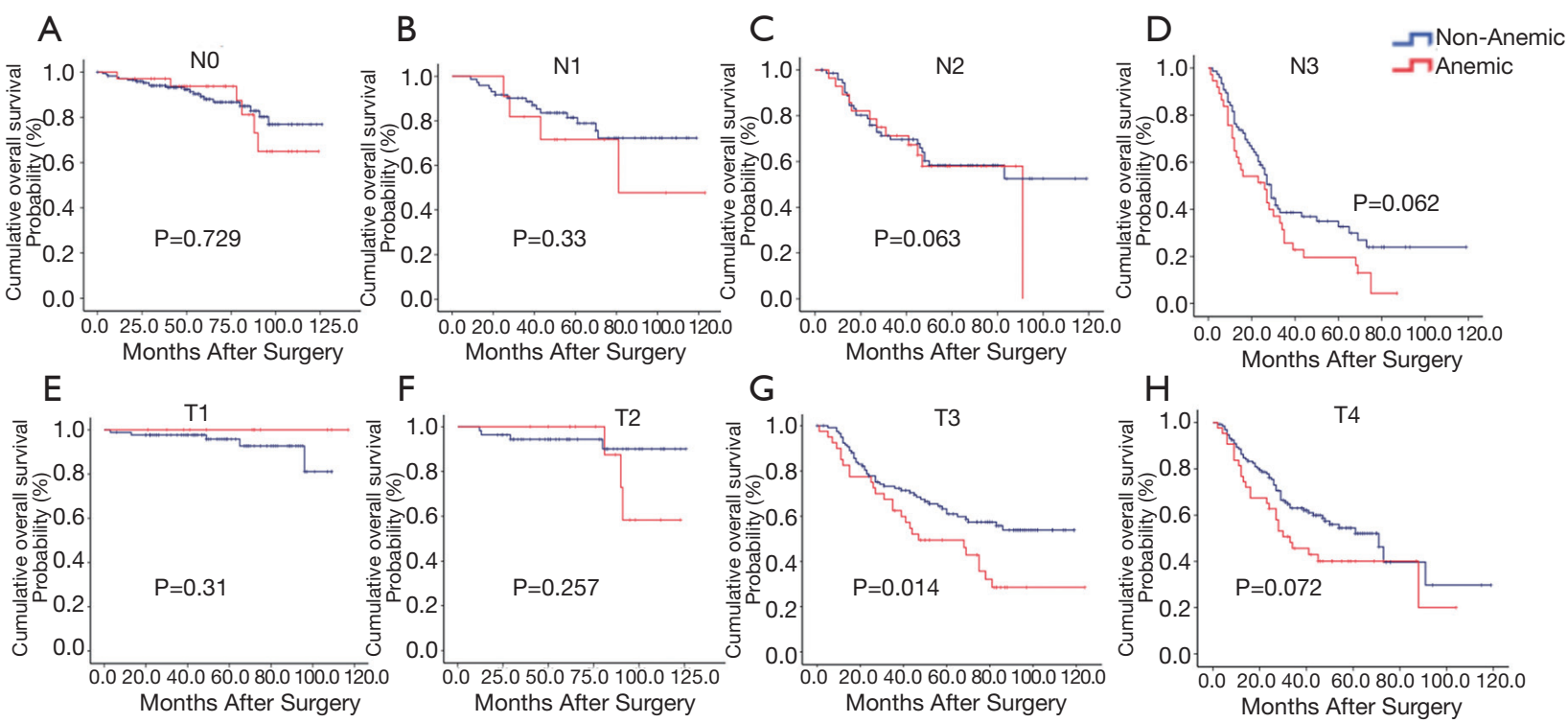

Figure 4 Kaplan-Meier curves of pretreatment anemia in nonhypoalbuminemia patients among groups: (A) pN0 stage; (B) pN1 stage; (C) pN2 stage; (D) pN3 stage; (E) pT1 stage; (F) pT2 stage; (G) pT3 stage; (H) pT4 stage.

Table 5 Univariate and multivariate analysis for overall survival in nonhypoalbuminemia patients

\begin{tabular}{|c|c|c|c|c|}
\hline \multirow{2}{*}{ Characteristics } & \multicolumn{2}{|c|}{ Univariate analysis } & \multicolumn{2}{|c|}{ Multivariate analysis } \\
\hline & $\mathrm{HR}(95 \% \mathrm{Cl})$ & $P$ value & $\mathrm{HR}(95 \% \mathrm{Cl})$ & $P$ value \\
\hline Age (years) & & 0.118 & & 0.520 \\
\hline$\leq 60$ & Referent & & Referent & \\
\hline$>60$ & $1.279(0.940-1.742)$ & & $1.114(0.801-1.550)$ & \\
\hline Male & Referent & & Referent & \\
\hline Female & $1.486(1.091-2.023)$ & & $1.094(0.771-1.554)$ & \\
\hline
\end{tabular}

Table 5 (continued) 
Table 5 (continued)

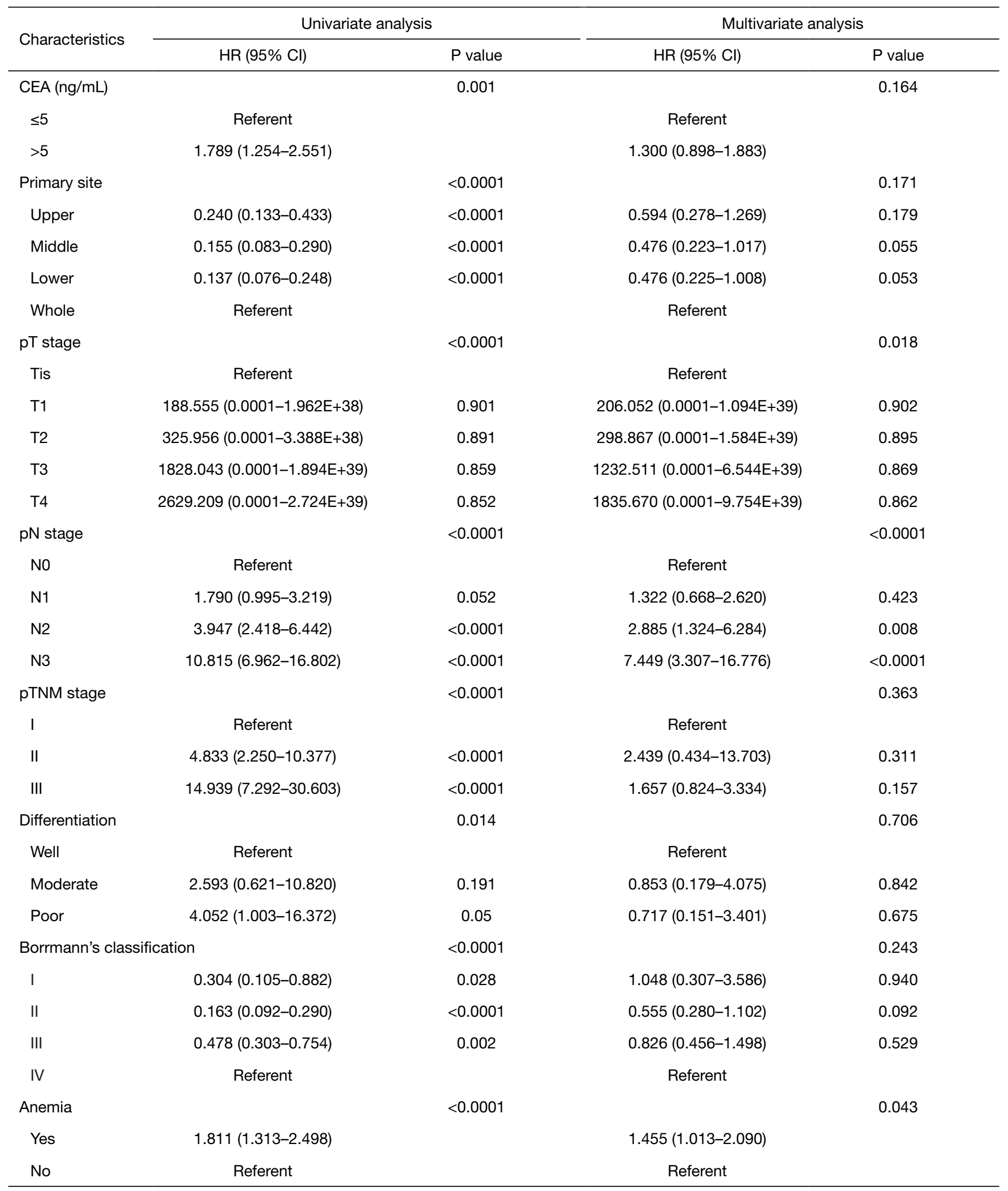

CEA, carcinoembryonic antigen; $\mathrm{HR}$, hazard ratio; $\mathrm{Cl}$, confidence interval. 
that severe pretreatment anemia was significantly associated with low albumin (15). Albumin constitutes up to two-third of total plasma protein and is responsible for the transport and binding of many molecules. Vascular damage caused by tumor can lead to loss of both albumin and hemoglobin. Inflammatory factors released by tumor enhance vascular permeability, which would induce a larger shift of albumin and hemoglobin from the vascular to the interstitial space. What is more, a lack of albumin might result in higher levels of free folate and vitamin B12, which would cause anemia. We divided our cohort into hypoalbuminemia and nonhypoalbuminemia groups to reduce the bias associated with chronic occult bleeding, alimentary obstruction, severe complications, malnutrition, weight loss, and renal dysfunction. We further verified the role of pretreatment anemia in patients with GC with nonhypoalbuminemia who underwent radical surgery. Therefore, our results might be more prudent in illustrating the prognostic importance of pretreatment anemia in GC.

Furthermore, after stratification by the AJCC/TNM stage, $\mathrm{pT}$ stage, $\mathrm{pN}$ stage and tumor size in patients with GC with nonhypoalbuminemia, pretreatment anemia further significantly stratified survival in the pT3 stage group and the tumor size $\geq 5 \mathrm{~cm}$ group. Both of these factors are associated with the malignancy of the tumor. These findings were consistent with those of previous studies $(16,17)$, which indicated that pretreatment anemia might be a potential biomarker for a high tumor burden and an aggressive tumor phenotype.

Over the past decades, researchers have focused on clarifying the potential mechanistic relationships between anemia and poor survival outcomes. To date, several hypotheses have been proposed. First, anemia can attenuate the capacity of the blood to transport oxygen, which results in a hypoxic tumor microenvironment (18). A hypoxic tumor microenvironment is a common feature in cancer and plays an important role in the unfavorable prognosis of solid tumors (19). Hypoxia-inducible factor-1 (HIF-1) is a key protein that responds to hypoxia. Its expression increases as the pathologic stages progress, and its expression is higher in poorly differentiated lesions than in welldifferentiated lesions $(20,21)$. HIFs or hypoxia signaling pathways are associated with many of the hallmarks of cancer (22), including angiogenesis (23), reprogramming energy metabolism (24), immune escape (24), activating invasion and distant metastasis (25), sustaining proliferative signaling, resisting cell death, and genome instability (26). Second, cancer-related inflammation has attracted increasing attention in recent years (27). Inflammatory cytokines released by tumor-associated macrophages, including tumor necrosis factor (TNF), interleukin (IL), and gamma interferon $(\gamma$-IFN), can not only inhibit the synthesis of erythropoietin (EPO) but also the release of stored iron and the proliferation of erythroid progenitor cells. Moreover, these inflammatory cytokines could lead to an increase in hepcidin (28), which binds to macrophages in the reticuloendothelial system and hinders the release of iron to transferrin. This is the so-called anemia of inflammation (29), which is typically unresponsive to iron interventions.

We examined the effect of pretreatment anemia on the OS of patients with GC with nonhypoalbuminemia undergoing curative resection in our innovative study. We found that pretreatment anemia was correlated with poor prognosis and could serve as an independent predictive factor of outcome. Stratification analyses by TNM stage and tumor size revealed that pretreatment anemia could provide better prognostic information for patients with a larger tumor size and pT3 GC than those with other stages. Moreover, evaluating patients with GC with nonhypoalbuminemia may obviate possible confounding factors associated with noncancer-related anemia, thus increasing the statistical power and providing more robust results.

Nevertheless, our study had some limitations. First, our study was a retrospective study; the cohort included patients who were treated at our center between January 1994 and December 2015. Over time, surgical procedures, surgical instruments, surgical skills, examinations of lymph nodes and adjuvant chemotherapies have all developed, which may have introduced bias. Second, one of the most important sources of heterogeneity-the heterogeneous treatment protocols among the included studies-may weaken our results. Third, we lacked cancer-specific survival and recurrence-free survival data. Therefore, further studies are required to verify our findings.

In conclusion, our data suggest that pretreatment anemia may serve as an independent prognostic factor in patients with advanced GC with nonhypoalbuminemia after radical gastrectomy, especially those with larger tumor size and pT3 disease.

\section{Acknowledgments}

The authors appreciate all supports from Gastrointestinal Surgery Center, First Affiliated Hospital, Sun Yat-sen University, Guangzhou, China. 
Funding: This study was supported by grants from Sanming Project of Medicine in Shenzhen (No. SZSM201911010). The Seventh Affiliated Hospital of Sun Yat-sen University (Shenzhen) Research Startup Fund, China (ZSQYHLKYJJ202006).

\section{Footnote}

Reporting Checklist: The authors have completed the STROBE reporting checklist. Available at https://dx.doi. org/10.21037/atm-21-1649

Data Sharing Statement: Available at https://dx.doi. org/10.21037/atm-21-1649

Conflicts of Interest: All authors have completed the ICMJE uniform disclosure form (available at https://dx.doi. org/10.21037/atm-21-1649). The authors have no conflicts of interest to declare.

Ethical Statement: The authors are accountable for all aspects of the work in ensuring that questions related to the accuracy or integrity of any part of the work are appropriately investigated and resolved. The study was conducted in accordance with the Declaration of Helsinki (as revised in 2013). Ethical approval was obtained from the Medical Ethics Committee of the Seventh affiliated Hospital of Sun Yat-sen University (No: KY-2020-024-01). All patient records and information were anonymized and deidentified prior to analysis. Individual consent for this retrospective analysis was waived.

Open Access Statement: This is an Open Access article distributed in accordance with the Creative Commons Attribution-NonCommercial-NoDerivs 4.0 International License (CC BY-NC-ND 4.0), which permits the noncommercial replication and distribution of the article with the strict proviso that no changes or edits are made and the original work is properly cited (including links to both the formal publication through the relevant DOI and the license). See: https://creativecommons.org/licenses/by-nc-nd/4.0/.

\section{References}

1. Rodgers GM 3rd, Becker PS, Blinder M, et al. Cancerand chemotherapy-induced anemia. J Natl Compr Canc Netw 2012;10:628-53.

2. Weiss G, Goodnough LT. Anemia of chronic disease. N
Engl J Med 2005;352:1011-23.

3. Gierth M, Mayr R, Aziz A, et al. Preoperative anemia is associated with adverse outcome in patients with urothelial carcinoma of the bladder following radical cystectomy. J Cancer Res Clin Oncol 2015;141:1819-26.

4. Cordella C, Luebbers HT, Rivelli V, et al. An evaluation of the preoperative hemoglobin level as a prognostic factor for oral squamous cell carcinoma. Head Neck Oncol 2011;3:35.

5. Bray F, Ferlay J, Soerjomataram I, et al. Global cancer statistics 2018: GLOBOCAN estimates of incidence and mortality worldwide for 36 cancers in 185 countries. CA Cancer J Clin 2018;68:394-424.

6. Shiozaki H, Shimodaira Y, Elimova E, et al. Evolution of gastric surgery techniques and outcomes. Chin J Cancer 2016;35:69.

7. Shen JG, Cheong JH, Hyung WJ, et al. Pretreatment anemia is associated with poorer survival in patients with stage I and II gastric cancer. J Surg Oncol 2005;91:126-30.

8. Liu X, Qiu H, Huang Y, et al. Impact of preoperative anemia on outcomes in patients undergoing curative resection for gastric cancer: a single-institution retrospective analysis of 2163 Chinese patients. Cancer Med 2018;7:360-9.

9. Li R, Wang X, Pan J, et al. The relationship between pretreatment anemia and survival time in patients with gastric cancer. Chinese Clinical Oncology 2008;13:704-8.

10. Network NCC. NCCN clinical practice guidelines in oncology: cancer and chemotherapy-induced anemia. 2011;2.

11. Zhang $Y$, Chen $Y$, Chen D, et al. Impact of preoperative anemia on relapse and survival in breast cancer patients. BMC Cancer 2014;14:844.

12. Ludwig H, Van Belle S, Barrett-Lee P, et al. The European Cancer Anaemia Survey (ECAS): a large, multinational, prospective survey defining the prevalence, incidence, and treatment of anaemia in cancer patients. Eur J Cancer 2004;40:2293-306.

13. Zhang S, Lu M, Li Y, et al. A lower haemoglobin level predicts a worse survival of patients with advanced gastric cancer. Clin Oncol (R Coll Radiol) 2014;26:239-40.

14. Gilreath JA, Stenehjem DD, Rodgers GM. Diagnosis and treatment of cancer-related anemia. Am J Hematol 2014;89:203-12.

15. Rausei S, Ruspi L, Galli F, et al. Peri-operative blood transfusion in gastric cancer surgery: prognostic or confounding factor? Int J Surg 2013;11 Suppl 1:S100-3.

16. Rink M, Sharifi N, Fritsche HM, et al. Impact of 
preoperative anemia on oncologic outcomes of upper tract urothelial carcinoma treated with radical nephroureterectomy. J Urol 2014;191:316-22.

17. Huang J, Feldman AS, Dong L, et al. Preoperative Anemia as an Independent Prognostic Indicator of Papillary Renal Cell Carcinoma. Clin Genitourin Cancer 2015;13:e353-60.

18. Vaupel P. The role of hypoxia-induced factors in tumor progression. Oncologist 2004;9 Suppl 5:10-7.

19. Xia X, Wang S, Ni B, et al. Hypoxic gastric cancer-derived exosomes promote progression and metastasis via MiR$301 \mathrm{a}-3 \mathrm{p} / \mathrm{PHD} 3 / \mathrm{HIF}-1 \alpha$ positive feedback loop. Oncogene 2020;39:6231-44.

20. Madeddu C, Gramignano G, Kotsonis P, et al. Microenvironmental M1 tumor-associated macrophage polarization influences cancer-related anemia in advanced ovarian cancer: key role of interleukin-6. Haematologica 2018;103:e388-91.

21. Schito L, Semenza GL. Hypoxia-Inducible Factors: Master Regulators of Cancer Progression. Trends Cancer 2016;2:758-70.

22. Hanahan D, Weinberg RA. Hallmarks of cancer: the next

Cite this article as: Jiang J, Ouyang J, Liu S, Chen J, Zhang H, Wang C, Wu W, Zhang C, He Y. The prognostic impact of pretreatment anemia in patients with gastric cancer and nonhypoalbuminemia undergoing curative resection: a retrospective study. Ann Transl Med 2021;9(13):1046. doi: 10.21037/atm-21-1649 generation. Cell 2011;144:646-74.

23. Jain RK. Antiangiogenesis strategies revisited: from starving tumors to alleviating hypoxia. Cancer Cell 2014;26:605-22.

24. Bristow RG, Hill RP. Hypoxia and metabolism. Hypoxia, DNA repair and genetic instability. Nat Rev Cancer 2008;8:180-92.

25. Rankin EB, Giaccia AJ. Hypoxic control of metastasis. Science 2016;352:175-80.

26. Harris AL. Hypoxia--a key regulatory factor in tumour growth. Nat Rev Cancer 2002;2:38-47.

27. Macciò A, Madeddu C, Gramignano G, et al. The role of inflammation, iron, and nutritional status in cancer-related anemia: results of a large, prospective, observational study. Haematologica 2015;100:124-32.

28. Nicolas G, Bennoun M, Devaux I, et al. Lack of hepcidin gene expression and severe tissue iron overload in upstream stimulatory factor 2 (USF2) knockout mice. Proc Natl Acad Sci U S A 2001;98:8780-5.

29. Ganz T. Anemia of Inflammation. N Engl J Med 2019;381:1148-57. 